\title{
Poemas fotográficos de Magela Ferrero: resistencias de la imagen y la escritura en Personas que tienen hambre (2011)
}

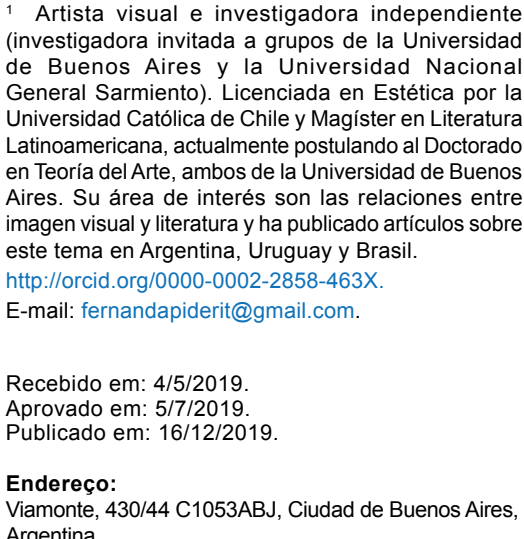

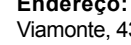

Argentina.

\author{
Magela Ferrero's Photographic Poems: writing and image \\ resistance in Personas que tienen hambre (2011) \\ Poemas fotográficos de Magela Ferrero: resistências da imagem \\ e da escrita em Personas que tienen hambre (2011) \\ María Fernanda Piderit ${ }^{1}$ \\ Universidad de Buenos Aires, Buenos Aires, Argentina.
}

\section{RESUMEN}

El presente artículo trata una obra de la artista Uruguaya Magela Ferrero dedde el punto de vista de la literatura. Puesto que su obra se conforma a partir del uso del espacio, textos y fotografías, consideramos que los estudios intermediales nos ofrecen una herramienta apropiada para abordarla críticamente y, de esta manera, expandir los horizontes de la crítica literaria hacia objetos que hoy podemos denominar dentro de las categorías genéricas de literatura expandida o literatura hors du livre.

PALABRAS CLAVES: Intermedialidad; Literatura; Fotografía; Artes latinoamericanas.

\section{ABSTRACT}

This article focus on an oeuvre by Uruguayan artist Magela Ferrero from a literary standpoint. As we consider it a kind of poetry conformed by space, texts and photography, we have chosen an intermedial perspective as a suitable tool to grasp it and, we think, expand literary criticism horizons. We also may think this kind of work part of relative new genres such as expand literature o literature hors du livre.

KEY WORDS: Intermediality; Literature; Photography, Latin-American arts.

\section{RESUMO}

Este artigo aborda a obra da artista uruguaia Magela Ferrero a partir da literatura. Dado que seu trabalho se conforma a partir do uso do espaço, de textos e de fotografias, consideramos que os estudos em multimeios oferecem uma ferramenta apropriada para abordá-la criticamente e, assim, expandir os horizontes da crítica literária para objetos que hoje se inserem em categorias genéricas como literatura expandida ou literatura "fora do livro" (hors du livre).

Palavras-chave: Estudos multimeios; Literatura; Fotografia; Arte latino-americana. 
We must accept that we are condemned on the basis os our perceptual organs and our central nervous systems, to live at least two realities that cannot be unified: in the auditory, one of the letters, and the visual, one of the numbers.

Vilém Flusser

\section{Prólogo}

a obra de la artista uruguaya Magela Ferrero frecuentemente está poblada Lde textos, imágenes, fotografías y otros objetos, dispuestos en libros de artista o exhibiciones en diversos espacios y su obra puede ser clasificada tanto como dentro de la literatura, la fotografía, las artes visuales y la música, dando cuenta de los límites difusos entre géneros y disciplinas tradicionalmente entendidos como campos autónomos. En este sentido, pensamos que una aproximación desde los estudios intermediales y la teoría de la imagen aplicada a la literatura pueden ser productivos a la hora de expandir los horizontes de la crítica literaria. Por lo tanto, entendemos la obra de Ferrero como una obra poética y a la literatura como una práctica artística que no se limita a las diversas formas de escritura contenidas, tradicionalmente, en el soporte libro. Las dificultades de esta aproximación son evidentes: un enfoque interdisciplinario exige el conocimiento de teorías que provienen de diferentes ámbitos, en nuestro caso de la teoría literaria, por un lado, y la teoría de la imagen, por otro, con especial énfasis en la filosofía de la fotografía. En particular, la pregunta sobre qué es la imagen no está resuelta y se sigue explorando. Ya en 1964, Roland Barthes -para tomar un filósofo ineludible para los estudios sobre la fotografía- se preguntaba:

¿Qué es la imagen? ¿Cuántos tipos de imagen hay? ¿Cómo clasificarla? ¿Dónde empieza la imagen? ¿Dónde termina? La misma palabra es muy huidiza y remite sin cesar, en un vaivén complicado, tan pronto al producto de una percepción física, como a una representación mental, tan pronto a una imaginería, como un imaginario; parece muy difícil detenerse en la imagen [...] (BARTHES, 2009; p. 81) (subrayado del autor)

La distinción que establece Barthes entre la percepción física y la mental -en parte producto de las lenguas que no hacen distinción entre estos dos tipos de imagen- sigue siendo relevante y nos concierne en cuanto a la importancia que obras como la de Ferrero le asignan al aspecto material de su obra. Este problema sigue siendo hoy cuestión de debate entres filósofos y teóricos diversas proveniencias. Una aproximación frecuente a la definición de la imagen ha sido oponerla a la escritura. James Elkins, frente a la pregunta ¿hay algo que fue una imagen y ya no lo es? (Mitchell, 2010; p. 137) responde:

[...] si delineas la imagen de esa manera, probablemente no te parecería adecuado ubicar a la escritura como uno de los otros términos, aunque la literatura esté dominada por numerosas versiones de la relación entre palabra e imagen, palabra/imagen (como tú dices), y tantas otras. O quizá la escritura sería eso que las imágenes una vez fueron y ya no son. (ELKINS, 2010; p. 137)

Esta respuesta de Elkins a W.J.T Mitchell nos da una pista de los problemas relevantes a la hora de discutir sobre la teoría de la imagen y, también, al momento de abordar la obra de Ferrero en este artículo: la relación entre escritura e imagen y la diferencia entre el decir y el mostrar, lo invisible y lo visible, el logos y la aesthesis, dicotomías que, como veremos más adelante, podemos interpretar como una lucha histórica que oscila entre diferentes técnicas culturales, lucha que al ponerse en evidencia, y al hacerse material, interpretamos como una forma de resistencia frente a las imágenes contrapensantivas, como las propone León Cannock, esas imágenes cuya función es reafirmar creencias heredadas en vez desestabilizarlas, frente a estas imágenes contra-pensantivas, obras como la de Ferrero nos ofrecen imágenes desestabilizadas, imágenes que no nos acercan a ningún tipo de verdad, sino que son resistencias a las formas de dominación (Cannock, 2018), imágenes, que como propone Barthes, frente a la cuales se produce movimiento, no 
detienen, si no que (re)mueven, que ponen en jaque las presupuestos que aceptamos sin mayor reflexión en nuestra vida cotidiana. También, pensamos, podemos encontrar en estas imágenes formas de literatura que ocupan el espacio público, que salen del libro, no sólo en un gesto de expansión, como lo solemos interpretar, si no también de re-ocupación, de re-cuperación, incluso de des-colonización, donde la experiencia del cuerpo se vuelve fundamental para completar las prácticas artísticas en el terreno social.

\section{Reflexiones sobre un artefactos literario}

Según el pensador checo-brasilero Vilém Flusser, el ser humano está condenado a la lucha histórica de la escritura contra la imagen, oscilando entre la textolatría y la idolatría, de la consciencia histórica -de una temporalidad linear- y la magia -de una temporalidad circular: con la invención de la escritura comienza la lucha contra la idolatría; con la invención de la fotografía, la lucha contra la textolatría (Flusser, 1983) ¿Qué pasa entonces cuando nos enfrentamos a obras tejidas de imágenes y textos? ¿qué pasa cuando la poesía está anudada en imágenes fotográficas? ¿qué pasa en obras como Personas que comen solas (2011) de la artista uruguaya Magela Ferrero? ¿qué pasa cuando la literatura -palabra escrita- se entremezcla con la fotografía -imagen visual- en tejidos, hibridaciones, imbricaciones, yuxtaposiciones que no se pueden -ni se deben- descoser, disgregar, desmembrar ni desacoplar a pesar de ser dos realidades de la percepción que no se pueden aunar? ¿qué pasa cuando dos temporalidades se reúnen, la linear y la circular, la diacrónica y la sincrónica? ¿cuando dos tipos de imágenes se yuxtaponen, la mental y la visual?

Podemos ver la imagen fotográfica como una suerte de ideograma complejo y particular, un ideograma que hibridiza conceptos y una forma particular de percibir la realidad, que cuando aislada nos detiene en el tiempo mágico de una potencial narración -un arte espacial como la pintura por ejemplo-, pero que cuando puesta en relación con otras imágenes fotográficas, constituyendo una serie o ensayo fotográfico, nos exige hacer un recorrido que, paso a paso, como girando las páginas de un libro, descubre -por no decir avanza- un nuevo aspecto de una narración propuesta. La poesía de Ferrero la podemos ver -encasillar- en el subgénero denominado en términos generales como poesía visual o, según Lars Elleström (2016), como poesía icónica puesto que, en sus reflexiones, toda poesía es visual dado que tanto los "textos" como las "imágenes" son percibidos con la vista; una de las diferencias entre el texto y la imagen, según el autor, serían las formas de crear significados y el grado de iconicidad de cada uno, es decir, de su relación de "semejanza" (resemblance) con las formas físicas de la realidad que nos rodea.

Figura 1. La lementa tiene em forma precisa, poema visual de Magela Ferrero em "Personas que comen solas" (2011).

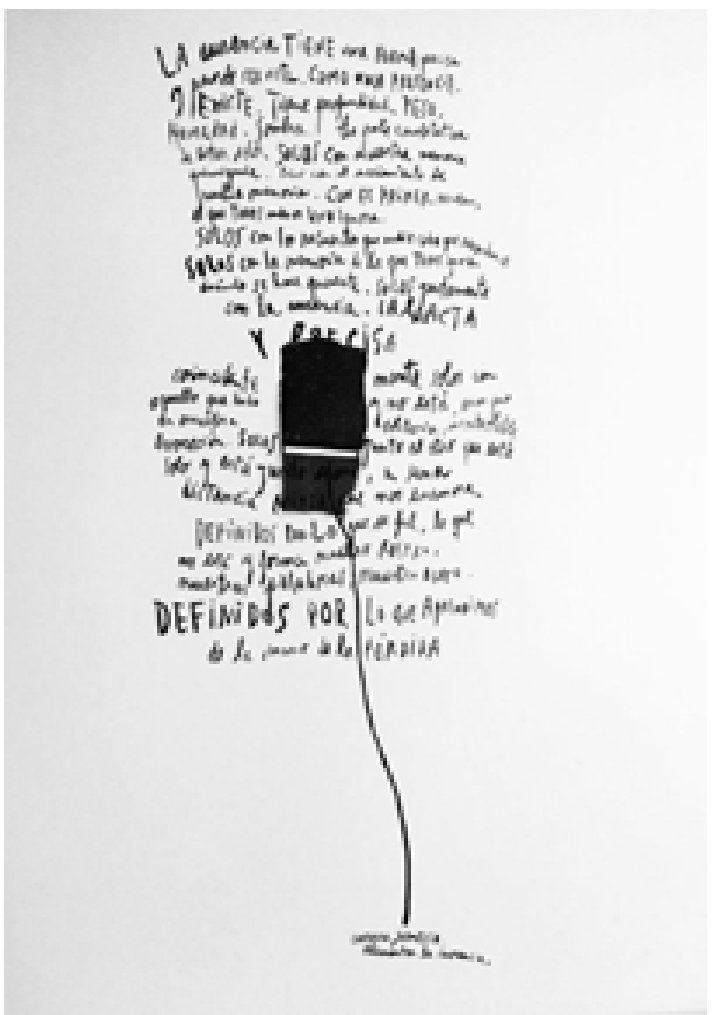

Fuente: poema visual de Magela Ferrero em "Personas que comen solas" (2011). 
El poema La ausencia tiene una forma precisa de Ferrero nos refiere a la visualidad concreta de la poesía, no sólo a hacer palpable el recuerdo -y el olvido-, la soledad y la pérdida, si no a la cualidad material de la literatura, a las formas que las palabras les dan a los conceptos de amor, memoria y soledad: las palabras son materia concreta que dan forma (informan) al poema y a las cosas. La literatura es, por lo tanto, visual. Hacer notar que la literatura es una forma de visualidad concreta es una tarea a la que muchos artistas se han abocado conscientemente desde principios de siglo XX, sobre todo a partir de las experimentaciones de las vanguardias históricas, desde algunos integrantes del movimiento Dadá y otro artistas, siendo el más reconocido -aunque por supuesto no el único ni el primero- en este ámbito Marcel Duchamp (Boîteen-valise, 1935-1941) junto a otros artistas como Georges Hugnet y Man Ray (La Septième Face de Dé, 1936), cuyas obras también han dado origen a las reflexiones sobre el libro de artista o el libro objeto y, más tarde, al libro fotográfico. El aspecto visual de la literatura en general no es considerado por la crítica literaria tradicional que, por el contrario, se concentra en el aspecto abstracto de las palabras, considerando a las representaciones visuales como ajenas a la literatura, pertenecientes a otros campos bien definidos, por ejemplo, la pintura:

Es cierto que la literatura tiene una dimensión visual propia, que se pueden entender fundamentalmente de dos maneras: como un despliegue gráfico del texto en la página y como capacidad de generar visiones en la imaginación del lector. Una fenomenología de la lectura nos revelaría el funcionamiento de estas imágenes mentales. Pero que hay que reconocer que existe una diferencia entre una imagen virtual de la imaginación y la imagen visible a los sentidos. Las formas de representación visual propias de la pintura o del cine son esencialmente ajenas a la literatura. Por ello, el problema que nos ocupa es el de la capacidad de la palabra de contener la imagen: es para la palabra que la imagen es fugaz, es a la representación verbal a lo que escapa" (MONEGAL, 1996, p.310)

Remitámonos a este texto de Antonio Monegal, escrito pocos años después de Picture Theory (1994) de W.J.T. Mitchell, considerado como una suerte de bisagra entre el giro lingüístico y el giro pictórico. Acá el aspecto visual al que se refiere el autor son, por una parte, el diseño ("despliegue gráfico del texto en la página") y a la imagen mental ("visiones en la imaginación del lector"), considerando a la primera, es decir a la "imagen visible a los sentidos" como "esencialmente ajena a la literatura". Monegal, en este caso, desde la crítica literaria, se aboca a analizar los "rastros" de visualidad que las palabras de la literatura evocan en la mente del lector; es decir, que para este tipo de análisis, la imagen visual de la literatura no es elemento ni esencial ni creador de significados: lo importante, en la literatura, es esa imagen mental intangible evocada por las palabras, que podríamos llamar imagen poética. Sin embargo, podemos observar que en el poema de Ferrero hay una insistencia en hacer notar el aspecto material de la visualidad que le da forma a estas imágenes, la ausencia tiene una forma bien precisa y la estamos viendo; por otro lado, al mismo tiempo que percibimos visualmente la forma física de la ausencia, vamos completando esta forma con la imagen mental que las palabras, dentro del poema, nos evocan: una doble dimensión de la imagen poética que no podemos atomizar. Sin embargo, a pesar de esta conjunción -amalgama diría Mario Bellatin - de palabras escritas e imagen visual en un objeto -por ahora el poema en cuestión- persiste en él una lucha entre la palabra escrita y la imagen visual, una resistencia que hace más compleja nuestra percepción y aprehensión del poema. Esta resistencia del objeto para ser aprehendido -con consecuencias políticas- se debe en parte a los diferentes modos de percepción de nuestros sentidos, como nos advierte Vilém Flusser al hablar de nuestra condena a vivir en, al menos, dos realidades irreconciliables: el mundo de las palabras y el mundo de las imágenes visuales. Lars Elleström nos dirá, por otro lado, que la diferencia radica en la forma de producir significado:

The distinctive feature of an image, compared to written text, is actually not that it is visual. If we say that there are "text" and "images" in a book, for instance, it is clear to see that both "text" and "images" are perceived by the eyes; the difference is that the "text" produces meaning mainly by means of symbolic (verbal) signs (based on convention), while the "images" produce meaning mainly via iconic signs (based on resemblance)." (ELLESTRÖM, 2016, p.440)

Desde los estudios intermediales y multimodales, donde se ubica Elleström , más importante y esclarecedor que la dicotomía de esta lucha entre lo verbal 
y lo visual -que no la niega del todo, pero le suma matices- es destacar la diferencia entre lo visual y lo icónico, donde lo visual corresponde a un modo sensorial y lo icónico a un modo semiótico que crea significados por "semejanza" -opuesto al simbólico por "convención"; por lo tanto, la diferencia estaría más bien entre la producción de sentido por medio de signos simbólicos o signos icónicos, porque tanto los textos como las imágenes visuales son percibidas por la vista para ser decodificadas según nuestras propias convenciones adquiridas -es decir, nuestro bagaje simbólico. El poema La ausencia tiene una forma precisa, por su parte, lo percibimos en primer lugar de una sola vez (espacial) como una "forma precisa" dibujada a través de palabras que la delimitan y la llenan para separarla del fondo; pero luego nos acercamos y procedemos a realizar un acto que tenemos desde hace tiempo automatizado: investigamos y recorremos las formas y la disposición de las palabras para decodificar el lenguaje escrito y le asignamos significado e imágenes mentales a las palabras que estamos leyendo: leemos en un sentido tradicional en un formato ajeno a la literatura y a la poesía porque además de ser visual y concreto -el poema-, no está en un libro, si no que organizado sobre una pared junto a otros poemas e imágenes que son parte de la obra en su conjunto.

Nos importa, entonces, destacar ahora que los poemas visuales de Magela Ferrero constituyen un cuerpo que está dispuesto no en las páginas de un libro -al modo de un libro de poesía que respeta para cada poema un espacio reservado en una página en blanco, el despliegue gráfico en la página-, si no en las paredes de una galería que, a diferencia del poema que hemos sacado de su contexto específico de exposición, invita al observador-lector a recorrer el espacio donde están desplegadas las páginas del libro de poemas, una obra literaria que podríamos llamar momentáneamente, entre otras clasificaciones genéricas posibles, una literatura fuera del libro (Rosenthal et Ruffel, 2010) , una literatura de algún modo performática; una literatura performática en el doble sentido de una literatura que ella misma actúa imprimiéndose una forma y construyendo sentido, así como de un agente externo que le va da dando forma y creando significados a partir de ella, un agente que llamaremos, mientras tanto, peregrino literario -el observador-lector que, al moverse en un determinado recorrido, reconstruye el espacio físico de esta literatura que está fuera de los límites del libro, pero dentro de un laberinto de múltiples senderos que expande los alcances de la crítica literaria:
The problem is not, finally, that literary critics use words like labyrinth game, and world as metaphors in their analyses of unicursal works but that this rhetoric seems to have blinded them to the existence of multicursal literary structures and to the possibility that the concept of labyrinth (in their post-Renaissance rendition) might have more analytic accuracy in connection with texts that function as game-worlds or labyrinths in a literal sense".(AARSETH, 2010; p.5)

Esta idea de la literatura como un laberinto de múltiples senderos -no podemos evitar recordar a Borges- donde el lector elige su recorrido en la construcción de sentido, como lo propusiera Julio Cortázar no solo en su libro Rayuela, sino aún más en la descripción de una máquina para leer Rayuela en La vuelta al día en ochenta mundos, la rayuela-o-matic, donde imagina ya el espacio físico y sus implementos materiales para llevar a cabo una lectura que estaba inspirada en la máquina para leer el libro Nouvelles impressions d'Afrique (1937) de Raymond Roussell y la Boîte-en-valise (1935-41) de Marcel Duchamp citada más arriba, esta idea de literatura que se construye en un espacio físico es llevada a su realización material en obras como las que estamos analizando, donde el lector-observador se transforma en un peregrino literario.

Una forma precisa sobre el fondo blanco de la pared hace presente a la ausencia, una figura conformada por palabras que llenan ese espacio vacío; esto es la imagen, la presencia de una ausencia:

We therefore could rephrase the presence leme absence, which still is the most lementary definition of images, in the following way: images are present in their media, but the perform an absence, which they make visible (BELTING, 2005; p. 313) 
Figura 2. Que no daremos por comer cuando tenemos hambre, poema fotográfico de Magela Ferrero em "Personas que comen solas" (2011).

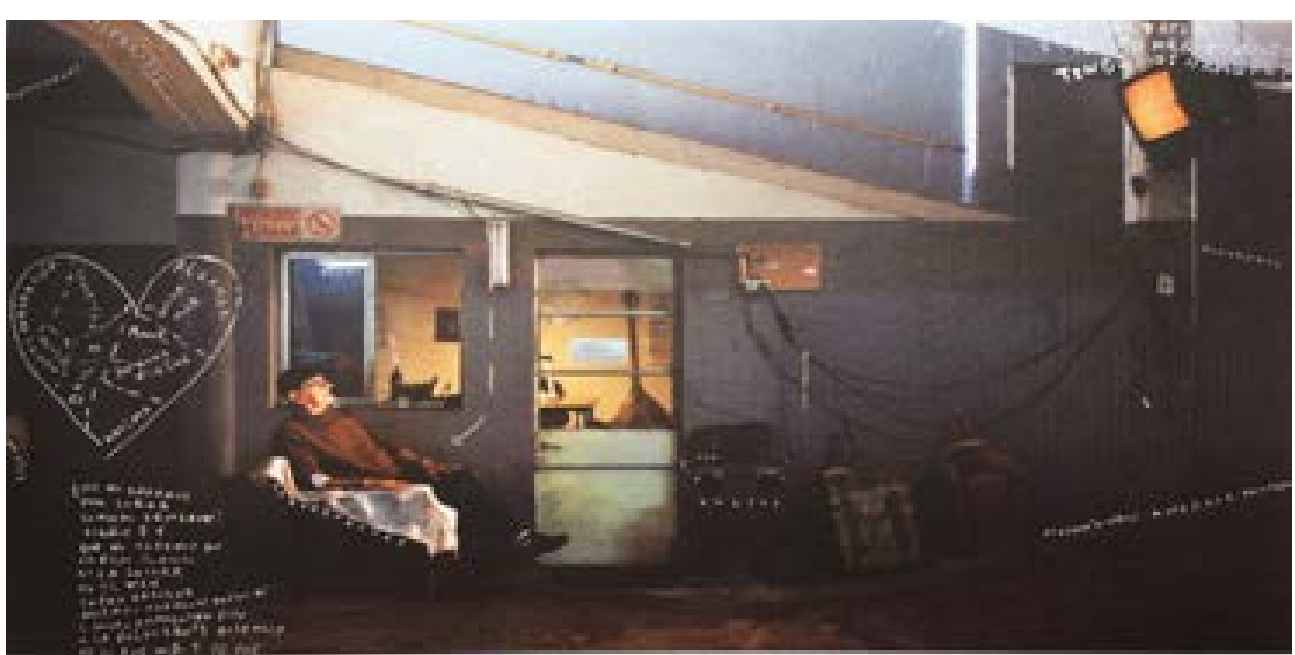

Fuente: poema fotográfico "Personas que comen solas” (2011), de Magela Ferrero

Ahora bien ¿qué pasa cuando esta imagen dialoga con imágenes fotográficas? En las obras poéticas de Ferrero que aquí tratamos nos encontramos con la interacción de textos, imágenes de palabras que se recortan sobre el fondo e imágenes fotográficas intervenidas con texto, como el poema fotográfico Que no daremos por comer cuando tenemos hambre, de la exposición -del libro desplegado y expuesto- "Personas que comen solas". La pregunta sobre la imagen acá también puede plantearse como: la imagen fotográfica ¿cómo hace visible lo invisible? ¿cómo se manifiesta la ausencia en la fotografía? 0 ¿por qué darle materialidad a la ausencia a través de imágenes fotográficas? ¿en qué se diferencia - o se parece- esta ausencia visible de otras formas de representación? Ferrero en estas obras poéticas teje una complicada red de relaciones entre diferentes medios, lenguajes y códigos. No solo la obra se abre como una laberinto de un recorrido incierto que el peregrino literario debe explorar de un lugar a otro mirando, caminando de un punto a otro, buscando los hilos que conectan los senderos, sino que se imbrican diferentes tipos de imágenes -poéticas y visuales, figurativas y fotográficas- con textos que se confunden en o dan forma a estas imágenes ¿cuál es la relación que establece la imagen de la forma precisa de la ausencia con las fotografías que se encuentran a su alrededor? ¿y cuál es la relación que los textos establecen con las fotografías en los que están insertos y viceversa: cuál es la relación de la fotografía con los textos que se confunden dentro de ella? ¿qué lugar ocupa, o siente que ocupa, el peregrino literario cuando se encuentra en medio de este laberinto?

Creemos que en este problema nos puede resultar útil metodológicamente establecer la trilogía que estaría formada por obra-medio-cuerpo y la diferencia entre el decir y el mostrar. Por un lado, el medio es el canal material y concreto por dónde se transmite sensorialmente la obra que es decodificada y reactualizada por el cuerpo de nuestro peregrino literario. Podemos afirmar que, desde esta aproximación, adoptamos el punto de vista del giro materialista, asumiendo, por ahora, que la producción de sentido y de conocimiento surge de la materia del medio ambiente que nos rodea y que nos irrita:

We deny Cartesian dualism by defining one of its terms. There is no "mental substance", everything is matter, and thinking itself arises out of matter. [...] Our knowledge come to us through "surface irritations", the points in our receptors whereas the various stimuli from the environment impinge. It is these which are the basis of our knowledge (DREYFUS et TAYLOR, 2015; p.3)

Negar el dualismo mente-cuerpo estaría en el centro de estas obras que se esfuerzan por poner en evidencia el aspecto material de la obra, lo que incluye el uso del espacio como agente creador de sentidos, así como la negación del libro como portador de un saber abstracto que oculta su materialidad olvidamos que el libro es un objeto concreto que porta en sí formas que son percibidas por la vista, las letras que arman el texto: entonces la literatura sale del libro para ocupar el espacio público e irritar nuestra piel con una red compleja de estímulos que activan nuestros sentidos y nuestra memoria colectiva para reconstruir, decodificar y dar significado a la materia que nos rodea. Esta irritación a los sentidos que nos produce la obra puede ser, en parte, la manifestación de esa resistencia entre dos o más medios, la escritura y la imagen -en particular la imagen fotográfica-, una obra imbricada que se 
resiste a ser aprehendida que pone en evidencia -hace visible, no oculta- sus medios de transmisión. La irritación a nuestros sentidos se debe, por otro lado, a lo que Flusser ya nos ha advertido: las imágenes y la escritura pertenecen a mundos diferentes, aunque los dos sean mediaciones entre el mundo y el ser humano: las imágenes le presentan el mundo al hombre, pero al hacerlo se interponen entre el mundo y el hombre hasta que el mundo es la imagen creada por el hombre, una imagen donde se pierde -ya no le sirve para reconocer el mundo- $y$, al estar perdido en las imágenes, los textos tratan de explicar las imágenes que explican el mundo, para que luego las imágenes intenten ilustrar los textos que intentan explicar las imágenes(Flusser, 1983); desde otra perspectiva, en estas obras se hace evidente la diferencia de dos técnicas culturales, las diferencias entre el decir y el mostrar: "Entonces, la pregunta por la imagen siempre concierne también a la diferencia entre aquello que se deja decir y aquello que no se deja decir, pero se muestra" (BOEHM, 2014; p. 25)

En la diferencia entre el mostrar y el decir lo que se debería buscar es una posible respuesta a la pregunta de cómo cada una de estas "técnicas culturales", en nuestra obra poética, crean sentido, sobre todo cómo crean sentido cuando están combinadas y con-fundidas entre sí: las formas de mostrar de la imagen y las formas de decir del texto se vuelven inseparables como las dos caras de una moneda, pero al mismo tiempo parecen ser mundos irreconciliables para nuestros sentidos, mundos donde sin embargo ninguno subordina al otro; entonces ¿cuál es la maquinaria que funciona detrás de ella y cómo esta máquina está mediando entre el mundo y yo, ser humano? La fotografía es una forma particular de mostrar dentro del mundo de las imágenes que, de acuerdo a las perspectivas teóricas donde nos estamos desenvolviendo, tiene un alto grado de iconicidad, entendida en este caso como el grado de semejanza con las formas físicas que reconocemos en la realidad externa que nos rodea, grado de semejanza que se establece comparado con otro tipo de imágenes visuales y otros medios. Este alto grado de iconicidad -además de la indocilidad- le atribuye a la fotografía una cualidad documental que, por historia y por convención, está incorporada a nuestra forma de percibirla como evidencia "objetiva" de la realidad. Aunque esta postura de la referencialidad -y la indocilidad- y objetividad de la fotografía pueda ser discutida, como lo ha sido y sigue siendo desde diversas disciplinas, todavía hoy, incluso conscientes de las manipulaciones a la que puede ser sometida cualquier imagen, su cualidad de documento de la realidad es el que prevalece cuando observamos una imagen fotográfica, incluso si ello sirve para hacer evidente que no lo es -por ejemplo, es uso de los memes en las redes sociales, donde justamente su alto grado de iconicidad sirve para desmentir y burlarse de y a través de su relación con la realidad. En el poema Que no daremos por comer cuando tenemos hambre nos enfrentamos a una fotografía que al primer golpe de vista identificamos, a grandes rasgos, como el de una persona mayor sentada en un espacio interior amplio mirando televisión, una imagen fácil de describir en tanto que su grado de iconicidad nos permite reconocer objetos de la realidad material sin problemas: un sillón, un hombre de edad, un televisor, una puerta, una ventana, una radio, etcétera. Si lo comparamos con el poema La ausencia tiene una forma precisa ¿qué forma tiene el poema? Podemos distinguir una figura que se recorta contra el fondo, pero ¿a qué se parece? ¿semejante a qué objeto de nuestra realidad material que podamos reconocer? No sabemos, pero el texto inserto en él, mismo texto que lo configura, nos dice que esa es la forma precisa de la ausencia. Y ¿qué forma tiene la fotografía?

A partir de estas observaciones, podríamos afirmar que una de las relaciones del lenguaje verbal escrito -entendido como signo simbólico y no como grafía, que también está presente en la escritura a mano que dibuja, no sólo escribecon la imagen visual en el poema La ausencia tiene una forma precisa es la de ayudarnos a/guiarnos/sugerirnos entender (aprehender) que esa figura que se recorta sobre el fondo es la forma material concreta y visible que tiene la ausencia, que la ausencia existe con todo su peso y profundidad, aspecto que antes de leer el poema nos era difícil de re-conocer: 
Figura 3.Transcripción del poema La ausencia tiene una forma precisa.

La ausencia tiene una forma precisa y puede ser vista. Como una presencia. Existe. Tiene profundidad. Peso.

Humedad. Sombra. Es parte constitutiva

de estar solos. Solos con nuestra memoria primigenia. Solos con el nacimiento de

nuestra memoria. Con el primer recuerdo, el que todos menos uno ignora.

Solos con los recuerdos que nadie sabe que recordamos

solos con la memoria de que todos ignoran cuándo se hace presente. Solos justamente

con la ausencia. La exacta

y precisa

coincidentemente solos con

aquello que hubo y no está, cosas que

en nuestra solitaria incontable

evocación. Solos junto al otro que está

solo y está junto a mi, a una

distancia nimia que nos enamora.

Definidos por lo que se fue, lo que

no está y forma nuestro rostro,

nuestras palabras, nuestro deseo.

Definidos por lo que aprendimos

de la mano de la pérdida.

Castello, Venezia

Alimentar la inocencia.

Fuente: archivo personal.

Por su parte, en el poema Que no daremos por comer la imagen fotográfica es intervenida con textos que desafían su estatuto documental y referencial. Si la imagen fotográfica tiene un significación muda (Boehm, 2014), es decir la imagen nos muestra algo través de un soporte material específico porque hay cosas que no se dejan decir, los textos entonces se empeñan en darle palabras a la imagen, pero al mismo tiempo que le prestan esa voz - que también nos habla de una ausencia fulgurante-, desarticulan su cualidad documental porque otras imágenes, esta vez poéticas, se infiltran, se enredan en la fotografía, de modo que el hombre sentado en el taller ya no es sólo un hombre sentado en un taller en el momento en que la fotógrafa disparó el obturador, sino que viene a ser la imagen poética de lo que es un hombre querido ¿y cómo es un hombre querido? ¿es una persona sola sentada frente a un televisor? ¿qué imagen trae nuestro peregrino literario de ser una persona querida? ¿y qué imagen queda después de leer el texto que acompaña al ser querido? ¿de las otras palabras que se desperdigan en el espacio fotográfico?

Figura 4. Recorte y transcripción de texto del poema Que no daremos por comer...

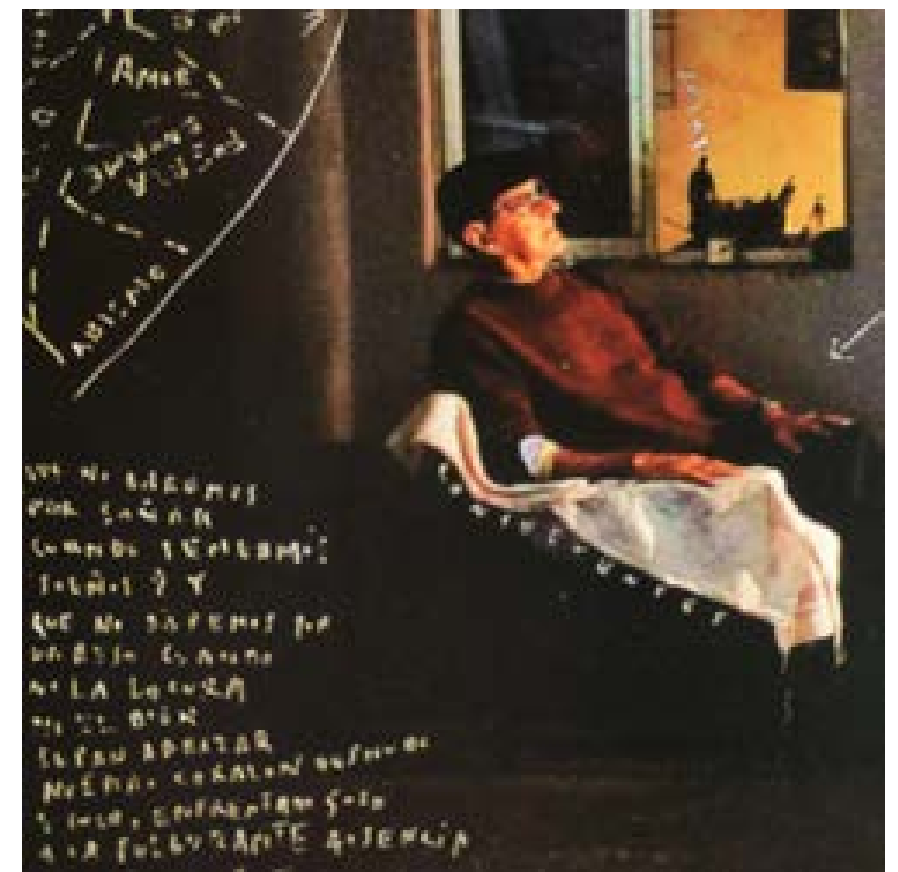

Que no daremos por soñar cuando tengamos sueños y que no daremos por un beso cuando ni la locura ni el bien sepan abrazar nuestro corazón desnudo

solo, enfrentado solo a la fulgurante ausencia de un ave [que] se fue

Decir que el texto acompaña a la imagen fotográfica en este poema no es exacto. Estas palabras están inscriptas en el espacio delimitado por el soporte de la fotografía: no están afuera de ella -tal como lo hemos hecho acá para hacer legible el texto en la figura 4-, si no confundidas en ella. Se considera que 
la relación entre escritura y fotografía existe desde que la fotografía apareció en nuestra cultura a mediados del siglo XIX, ya sea como textos escritos en el reverso de una fotografía indicando, por ejemplo, nombres, lugares, fechas, ya sea como títulos, epígrafes, indicaciones, explicaciones o incluso ensayos de más largo aliento. En este sentido, pensadores de la fotografía provenientes de diversas prácticas y aproximaciones teóricas sostienen que, de hecho, debido a que la imagen fotográfica es tan abierta a la interpretación -polisémica dirá R. Barthes- por parte del observador, necesita un texto que ancle $e^{2}$ su significado: en fotografías familiares, publicidad, artículos periodísticos, libros temáticos, etcétera. En la mayoría de estos casos, la función del texto será la de guiar ideológicamente la interpretación del observador/lector dentro de su propias convenciones sociales y culturales: en la re-actualización de la imagen fotográfica por parte del observador, que la ve según las convenciones y códigos aprendidos en su medio social y cultural, el texto escrito le dirá qué ver y cómo ver la imagen, pero siempre tratando de mantener la autonomía -y esto no quiere decir "pureza"- de cada medio: no se mezclan ni confunden, si no que se acompañan, dialogan o articulan con diferentes modos y grados de combinación o subordinación. Sin embargo, en este poema y otros de las series que estamos estudiando, texto e imagen se confunden entre sí materialmente. Podemos encontrar en otras obras literarias esta tensión entre imagen y escritura cuyos sentidos solo son-idealmente- aprehendidos o creados si se mantienen los dos medios en relación -por ejemplo, una novela gráfica o un libro fotográfico-, donde un medio depende del otro sin subordinarse, pero en la disposición espacial mantienen sus límites bien definidos. En nuestro caso, los poemas de Ferrero comparten con otros definidos como poemas visuales, concretos o icónicos la característica de que imagen y texto se perciben visualmente como el mismo objeto. En este punto volvemos resaltar la insistencia que pone la obra sobre la materialidad de la experiencia del

Recordamos este concepto - anclaje y relevo- de las reflexiones de Roland Barthes: en su texto La retórica de la imagen (1964), Barthes distingue dos funciones del mensaje lingüístico (que transmite la escritura que acompaña a una imagen): anclaje relevo. La función de anclaje nombra la cosa, dice lo que es, para poder fijar la cadena flotante de significados potenciales de una imagen y guía su interpretación. Es una función de control. La función de relevo, menos frecuente, complementa los sentidos que no se encuentran en la imagen. Por su parte, Walter Benjamin ya en Breve historia de la fotografía (1931) hacía alusión a la necesidad del éígrafe que acompñe a la fotografía; más o menos lo mismo indica Pierre Bourdieu en Un art moyen (1965) a propósito de la necesidad de un epígrafe en las fotografías, entre otros autores y pensadores. sujeto: a través del esfuerzo que nuestro peregrino debe hacer para recorrer el espacio, reconocer medios y lenguajes, decodificarlos y darles sentido, es donde la tensión entre el decir y el mostrar y los procesos ocultos de lectura de un libro se hacen evidente; dónde el proceso de leer se transforma en una experiencia física que involucra a todo el cuerpo de nuestro peregrino.

\section{Epílogo}

A la tensión que se produce en la articulación de escritura e imagen en un mismo objeto la entendemos como un dispositivo ${ }^{3}$ de resistencia. A pesar de que imagen fotográfica y texto convivan desde la aparición de la fotografía, esta convivencia no está libre de una lucha de poder de los valores sociales y culturales -por lo tanto político- que le asignamos histórica y culturalmente a la imagen visual y la palabra escrita; y junto a la escritura, al libro como soporte privilegiado para la transmisión de narrativas -ya sea históricas, documentales y ficcionales-y, principalmente, conocimiento. Este privilegio de la escritura -del libro- sobre la imagen visual se sostiene en el paradigma logocéntrico occidental, a pesar de la proliferación de imágenes sobre la que algunos teóricos nos advierten hace varias décadas. Esta advertencia sobre la proliferación de la imagen actualmente es sintomática del miedo iconoclasta del logocentrismo que considera a la escritura como herramienta del intelecto y de la razón discursiva y abstracta en oposición a la imagen:

[...] la imagen no solamente transmite pulsiones, tabúes, afectos, fuerzas irracionales e instintivas (al menos así se postula), si no que también y sobre todo se propaga de una manera no controlada, lo cual solamente puede inquietar a toda ideología organizada [...] (BARTHES, 2009; p. 48)

Frente a la definición de dispositivo de Giorgio Agamben como "cualquier cosa que de algún modo tenga la capacidad de capturar, orientar, determinar, interceptar, modelar, controlar y asegurar los gestos, las conductas, las opiniones y los discursos de los seres vivientes", un dispositivo de resistencia es un dispositivo de profanación que desacraliza, en este caso, a la escritura y el libro como controladores de la imagen. 
La escritura, entonces, es un dispositivo que controla a la imagen y, cuando se le escapa de control, cuando las relaciones entre escritura e imagen se tensan, se produce la resistencia a este poder de dominación de un medio sobre el otro. La escritura trata de dominar a la imagen porque las imágenes pueden ser peligrosas. Nos dice Joan Fontcuberta:

Como si fueran impelidas por la tremenda fuerza de un acelerador de partículas, las imágenes circulan por la red a una velocidad de vértigo; han dejado de tener el papel pasivo de la ilustración y se han vuelto activas, furiosas, peligrosas... (FONTCUBERTA, 2016; p. 8)

Roland Barthes en la década de los años sesenta y Joan Fontcuberta a principios del siglo XXI dan cuenta del mismo miedo cultural sobre la proliferación a velocidades antes desconocidas de la imagen en descontrol: expresión de la lucha con la que hemos empezado este artículo entre textolatría e idolatría y que sostiene la dicotomía entre escritura e imagen visual en el mundo occidental que privilegia, aún hoy, el pensamiento abstracto. Frente a esta iconoclasia que mantiene las dicotomías maniqueas, la literatura contemporánea, o parte de ella, se sale del libro para constituirse en un artefacto literario y un dispositivo de barricada o resistencia frente a la hegemonía de la palabra escrita en la literatura.

\section{Corpus}

Personas que comen solas. 2011

Centro de Fotografía de Montevideo

Uruguay

\section{Bibliografía}

AARSETH, Espen J. Introduction: Ergodic Literature en Cybertext: Perspectives on Ergodic Literature. Baltimore: The Jonhs Hopkins University Press, 1997.
BARTHES, Roland. La Torre Eiffel. Textos sobre la imagen. Buenos Aires: Paidós Comunicación, 2009. BARTHES, Roland. Rhétorique de l'image. École pratique des hautes études 6e section, 1964. BARTHES, Roland. La cámara lúcida. Buenos Aires: Paidós, 2009.

BENJAMIN, Walter. Pequeña historia de la fotografía. In: BENJAMIN, Walter. Conceptos de filosofía de la historia. La Plata, Argentina: Terramar, 2007.

BOEHM, Gottfried. Decir y mostrar: elementos para una crítica de la imagen. Publicaciones Digitales, consulta 16 de febrero de 2019. Disponible: http://www.ebooks.esteticas.unam. $\mathrm{mx} /$ items/show $/ 9$

BOURDIEU, Pierre. Photography a Middle-brow Art. California: Stanford University Press. (Original publicado en 1965, Les Éditions de Minuit como Un art moyen), 1990.

CANNOCK, A. León. El pensamiento de las imágenes. Anotaciones sobre la performatividad de las imágenes y el arte contemporáneo. In: CANNOCK, A. León. Artículos de investigación sobre fotografía, Centro de Fotografía de Montevideo, 2018.

DREYFUS, Hubert y Charles Taylor. Retrieving realism. Harvard University Press, UK, 2015 https://doi.org/10.4159/9780674287136

ELKINS, James. Un seminario sobre la teoría de la imagen. Estudios visuales: Ensayo, teoría y crítica de la cultura visual y el arte contemporáneo, n. 7, p. 132-173, 2010.

ELLESTRÖM, Lars. The modalities of media: a model for inderstanding intermedial relations In: ELLESTRÖM, Lars. Media Borders, Multimodality and Intermediality. Houndmills: Palgrave Macmillan, 2010. p. 11-48. https://doi.org/10.1057/9780230275201

ELLESTRÖM, Lars. Photography and Intermediality: Analytical Perspectives on Notions Referred to by the term "photography". Semiotica, n. 197, p. 153-169, 2013. https://doi.org/10.1515/sem2013-0086

FLUSSER, Vilém. Hacia una filosofía de la fotografía. México: Sigma, 2002.

FLUSSER, Vilém. Does writing have a future? Translated Nancy Ann Roth. Mineápolis: University of Minnesota Press, 2011. https://doi.org/10.5749/minnesota/9780816670222.001.0001

FONTCUBERTA, Joan. La furia de las imágenes. Notas sobre postfotografía. Barcelona: Galaxia Gutenberg, 2016 
HORSKOTTE, Silke; PEDRI, Nancy. Introduction: Photographic Interventions. Poetics Today, Durham, v. 29, n. 1, p. 1-29, 2008. https://doi.org/10.1215/03335372-2007-015

MITCHELL, J. W. T. Teoría de la imagen. Madrid: Ediciones Akal, 2009.

MONEGAL, Antonio. La imagen fugaz: el rastro de la visualidad en la escritura. Moenia: Revista lucense de lingüística e literatura, Santiago de Compostela, v. 2, p. 309-326, 1996. ISSN 1137-2346.

RAJEWSKI, Irina O. Intermediality, intertextuality, and remediation: a literacy perspective on intermediality. Intermedialités, [s. l.], n. 6, p. 43-64, Automme 2005. https://doi. org/10.7202/1005505ar

ROSENTHAL, Olivia; RUFFE, Lionel. Introduction en La littérature exposée. Les écritures contemporaines hors du libre. Revista Littérature, n. 160, dic., 2010. 